\title{
Clinicopathological study of $\mathrm{ABO}$ blood types in prostate cancer
}

\author{
Sushma Shankar ${ }^{1, *}$, CSBR Prasad ${ }^{2}$ \\ ${ }^{\mathbf{1}}$ Assistant Professor, Dept. of Pathology, East point College of Medical Sciences and Research Centre, Bangalore, Karnataka, \\ ${ }^{2}$ Professor, Dept. of Pathology, Sri Devaraj Urs Medical College, Kolar, Karnataka, India \\ *Corresponding Author: Sushma Shankar \\ Email: dr.sushma1985@gmail.com
}

Received: $30^{\text {th }}$ April, 2018

Accepted: $3^{\text {rd }}$ May, 2018

\begin{abstract}
Aim: To study the association between the ABO blood groups and clinicopathological features in cases of prostate cancer (PCa). Materials and Methods: Fifty cases of $\mathrm{PCa}$, diagnosed on transurethral resection of prostate chips were a part of the study. Cases were classified into low risk and high risk categories and these categories were compared with the clinicopathological features and $\mathrm{ABO}$ blood groups.

Results: In the study of 50 cases, 44 cases belonged to the high risk category with $33(75 \%)$ patients being of non $\mathrm{O}$ blood group and $11(25 \%)$ being of the $\mathrm{O}$ blood group. Patients of non $\mathrm{O}$ group had an increased risk of aggressive PCa on comparison with the blood type $\mathrm{O}$. Chi sqaure test showed no significant difference between the non $\mathrm{O}$ and $\mathrm{O}$ groups regarding PSA value, Gleason score, tumor stage, node positivity and bone metastasis individually $(\mathrm{p}=0.418, \mathrm{p}=0.967, \mathrm{p}=0.506, \mathrm{p}=0.775, \mathrm{p}=0.549$. $)$ However within the high risk category, a statistically significant value was found for non $\mathrm{O}$ blood group against $\mathrm{O}$ groups $(\mathrm{p}=0.04)$ which was further proven by regression analysis.

Conclusion: In this study, non O blood types (especially $\mathrm{A}$ and $\mathrm{B}$ but not $\mathrm{AB}$ ) were found to be independent predictors for high risk $\mathrm{PCa}$ and $\mathrm{O}$ blood type patients had a low risk of aggressive $\mathrm{PCa}$ thus emphasising the importance of blood typing in patients with PCa.
\end{abstract}

Keywords: Prostate cancer (PCa), ABO blood type, O blood type, Non O blood type.

\section{Introduction}

Prostate cancer (PCa) is the second common type of cancer and stands in the sixth position amongst cancer related deaths in men worldwide. The number of new PCa cases is expected to reach 1.7 million by 2030 with 4,99,000 new deaths. ${ }^{1}$

Unlike the previous belief of PCa being an entity of the western world, developing countries like India are fast catching up in numbers due to many factors likemoderrnised life style, increased disease awareness, increased life expectancy and access to medical facilities. $\mathrm{PCa}$ is recorded the second common site of cancer among males in India. ${ }^{2}$

The prognostic role of Clinical (TNM) stage, prostate-specific antigen (PSA) levels and Gleason score on biopsy specimens is far beyond established in $\mathrm{PCa}$. With raising incidence of $\mathrm{PCa}$, it is the need of the hour to identify possible additional prognostic factors like the ABO blood groups which may help in further management of these cases.

A or B blood group antigens are complex carbohydrate molecules that are present on the RBC membrane. They determine the blood group of a person. In addition to their expression on the RBC surface, they are also expressed on the surface of epithelium, sensory neurons, platelets, and the vascular endothelium; thus extending its clinical significance beyond transfusion medicine. ${ }^{3} \mathrm{ABO}$ blood groups have an association with non neoplastic diseases like cardiovascular diseases, infectious diseases, peptic ulcer and malignancies like carcinoma pancreas, epithelial ovarian tumors, renal cell carinomas, nasopharyngeal cancers and skin cancers ${ }^{4}$. For example, it was shown that non $\mathrm{O}$ blood groups are an important risk factor for developing gastric and pancreatic cancers. $^{4}$

$\mathrm{ABO}$ blood group types as a risk factor for cancers like gastric and pancreatic cancers have been extensively studied, whereas studies with regard to $\mathrm{ABO}$ blood types and $\mathrm{PCa}$ are seldom. A single study showed no association between blood type and risk of PCa. ${ }^{5}$ On the contrary a positive association has been observed in another study. ${ }^{3}$ Based on these facts and controversies, the present study was undertaken to establish the association if any between $\mathrm{ABO}$ blood group types and clinicopathological features.

\section{Materials and Methods}

Fifty cases of primarily diagnosed, pathologically confirmed PCa were a part of the study. The study was undertaken in the pathology department of Sri Devaraj Urs Medical College. The source of data was the transurethral resection of prostate chips (TURP) samples which were sent from the Urology department of the attached hospital. The clinical history of age, hypertension, diabetes, TNM stage, serum PSA levels and $\mathrm{ABO}$ blood types were obtained from the clinical case file database and the pathological data of gleason score and grade were collected from pathology file database. The American Joint Committee on Cancer (AJCC) TNM classification of malignant tumors 2002 was used to assess the clinical TNM stage and ISUP 
classification of 2005 was used for gleason scoring and grading. ${ }^{6}$

PCa patients who had other cancers and cases which lacked complete clinical and pathological information were excluded from the study.

The subjects were stratified into two risk categories: the low risk category and the high-risk category. This was based on the PSA values, Gleason score, and TNM stage. PSA $\leq 30 \mathrm{ng} / \mathrm{ml}$, Gleason Score $\leq 7$, and TNM stage $\leq \mathrm{T} 2 \mathrm{~b}$ were categorised into low risk and high risk was defined by PSA $>30 \mathrm{ng} / \mathrm{ml}$, Gleason Score $\geq 8$, or clinical stage $\geq \mathrm{T} 2 \mathrm{c}$.

\section{Statistical Analysis}

The data was entered into the SPSS software (version 20.0) and was analysed by suitable tests. Variables were expressed as mean \pm standard deviation (SD) or as numbers and percentages depending on the type of variable in use. Students independent t-test and chi-square test were used for analysing quantitative and qualitative data respectively. Logistic regression analysis was used to find the association between different blood types and the high risk category of PCa. Multivariate analysis was performed after adjusting for the confounding factors. $P$ value of $<0.05$ was considered to be of statistical significance.

\section{Results}

Table 1: Association of clinicopathological characters with the low \& high risk categories of PCa

\begin{tabular}{|c|c|c|c|c|}
\hline Characters & $\begin{array}{c}\text { All Subjects } \\
(\mathbf{n}=50)\end{array}$ & $\begin{array}{c}\text { Low risk category } \\
(n=6)\end{array}$ & $\begin{array}{c}\text { High risk category } \\
(n=44)\end{array}$ & $P$ value \\
\hline Age & $66.2 \pm 9.4$ & $70 \pm 0.2$ & $65.68 \pm 9.9$ & 0.028 \\
\hline Hypertension & $15(30 \%)$ & $2(4 \%)$ & $13(26 \%)$ & 0.849 \\
\hline Diabetes mellitus & $13(26 \%)$ & $2(4 \%)$ & $11(22 \%)$ & 0.191 \\
\hline PSA & & & & $<0.001$ \\
\hline$<30 \mathrm{ng} / \mathrm{ml}$ & $8(16 \%)$ & $5(10 \%)$ & $3(6 \%)$ & \\
\hline$>30 \mathrm{ng} / \mathrm{ml}$ & $42(84 \%)$ & $1(2 \%)$ & $41(82 \%)$ & \\
\hline Gleason score & & & & $<0.001$ \\
\hline$</=6$ & $8(16 \%)$ & $6(12 \%)$ & $2(4 \%)$ & \\
\hline 7 & $14(28 \%)$ & $0(0 \%)$ & $14(14 \%)$ & \\
\hline $8-10$ & $28(56 \%)$ & $0(0 \%)$ & $28(28 \%)$ & \\
\hline \multicolumn{5}{|l|}{ Stage } \\
\hline Tumor & & & & $<0.001$ \\
\hline$</=\mathrm{T} 2 \mathrm{~b}$ & $12(24 \%)$ & $6(12 \%)$ & $6(12 \%)$ & \\
\hline$>/=\mathrm{T} 2 \mathrm{c}$ & $38(76 \%)$ & $0(0 \%)$ & $38(76 \%)$ & \\
\hline Node & & & & 0.221 \\
\hline No & $41(82 \%)$ & $6(12 \%)$ & $35(70 \%)$ & \\
\hline N1 & $9(18 \%)$ & $0(0 \%)$ & $9(18 \%)$ & \\
\hline Metastasis & & & & 0.709 \\
\hline M0 & $49(98 \%)$ & $6(12 \%)$ & $35(70 \%)$ & \\
\hline M1 & $1(2 \%)$ & $0(0 \%)$ & $1(2 \%)$ & \\
\hline ABO type & & & & 0.811 \\
\hline $\mathrm{O}$ & $14(28 \%)$ & $2(4 \%)$ & $12(24 \%)$ & \\
\hline $\mathrm{A}$ & $16(32 \%)$ & $2(4 \%)$ & $14(28 \%)$ & \\
\hline B & $14(28 \%)$ & $2(4 \%)$ & $12(24 \%)$ & \\
\hline $\mathrm{AB}$ & $6(12 \%)$ & $0(0)$ & $6(12 \%)$ & \\
\hline O/ Non O type & & & & 0.662 \\
\hline $\mathrm{O}$ & $13(26 \%)$ & $2(4 \%)$ & $11(22 \%)$ & \\
\hline Non $\mathrm{O}$ & $37(74 \%)$ & $4(8 \%)$ & $33(66 \%)$ & \\
\hline
\end{tabular}

50 pathologically confirmed cases of cancer prostate were included in the study with a mean age of $66.2 \pm 9.4$ years. The tumor stage of cases was as follows: T1 (6 cases), T2a (4 cases), T2b (6 cases), T2c (6 cases), T3 (20 cases), and T4 (8 cases). 14(28\%) cases were blood group $\mathrm{O}, 16(32 \%)$ cases were group A, 14(28\%) cases were group B and 6(12\%) were group $\mathrm{AB}$. Patients with advanced age, PSA value of more than 30 , gleason score of more than 7 and the clinical tumor stage of $>/=\mathrm{T} 2 \mathrm{c}$ had increased risk of $\mathrm{PCa}$ and had significant $\mathrm{P}$ value less than 0.05 , however we did not find a significant association between the different risk groups and $\mathrm{ABO}$ blood types ( $\mathrm{p}$ value $=0.811$ ). Table 1 shows a summary of the association between the clinicopathological variables and different risk categories with a significant $\mathrm{P}$ value written in bold. 
Table 2: Pathological characters of PCa patients stratified by blood group types

\begin{tabular}{|c|c|c|c|c|c|c|c|}
\hline \multirow[t]{2}{*}{ Characters } & \multicolumn{4}{|c|}{ ABO type } & \multirow[t]{2}{*}{ Non $O$ type } & \multirow{2}{*}{$\begin{array}{c}P \\
\text { value }^{1}\end{array}$} & \multirow{2}{*}{$\begin{array}{c}\mathbf{P} \\
\text { value }^{2}\end{array}$} \\
\hline & $\mathbf{O}$ & $\mathbf{A}$ & B & $\mathbf{A B}$ & & & \\
\hline PSA & & & & & & 0.666 & 0.418 \\
\hline$<20$ & $3(21.4 \% 0$ & $3(18.8 \%)$ & $2(14.3 \%)$ & $0(0 \%)$ & $5(13.5 \%)$ & & \\
\hline$>20$ & $11(26.2 \%)$ & $13(31 \%)$ & $12(28.6 \%)$ & $6(14.3 \%)$ & $32(100 \%)$ & & \\
\hline Gleason score & & & & & & 0.297 & 0.967 \\
\hline$</=6$ & $2(14.3 \%)$ & $4(25 \%)$ & $2(14.3 \%)$ & $0(0 \%)$ & $6(16.2 \%)$ & & \\
\hline 7 & $4(28.6 \%)$ & $4(25 \%)$ & $2(14.3 \%)$ & $4(66.7 \%)$ & $10(27 \%)$ & & \\
\hline $8-10$ & $8(57.1 \%)$ & $8(50 \%)$ & $10(71.4 \%)$ & $2(33.3 \%)$ & $21(56.8 \%)$ & & \\
\hline \multicolumn{8}{|l|}{ Stage } \\
\hline Tumor & & & & & & 0.758 & 0.506 \\
\hline$</=\mathrm{T} 2 \mathrm{~b}$ & $4(28.6 \%)$ & $4(25 \%)$ & $2(14.3 \%)$ & $2(33.3 \%)$ & $8(21.6 \%)$ & & \\
\hline$>/=\mathrm{T} 2 \mathrm{c}$ & $10(71.4 \%)$ & $12(75 \%)$ & $12(85.7 \%)$ & $4(66.7 \%)$ & $29(78.4 \%)$ & & \\
\hline Node & & & & & & 0.676 & 0.775 \\
\hline N0 & $12(85.7 \%)$ & $14(87.5)$ & $10(83.2 \%)$ & $5(71.4 \%)$ & $30(81.1 \%)$ & & \\
\hline N1 & $2(14.3 \%)$ & $2(12.5 \%)$ & $4(28.6 \%)$ & $1(16.7 \%)$ & $7(18.9 \%)$ & & \\
\hline Metastasis & & & & & & 0.058 & 0.549 \\
\hline M0 & $14(100 \%)$ & $16(100 \%)$ & $14(100 \%)$ & $5(98 \%)$ & $36(97.3 \%)$ & & \\
\hline M1 & $0(0)$ & $0(0)$ & $0(0)$ & $1(16.7 \%)$ & $1(2.7 \%)$ & & \\
\hline $\begin{array}{l}\text { High risk } \\
\text { category }\end{array}$ & $12(27.3 \%)$ & $14(31.8 \%)$ & $12(27.3 \%)$ & $6(13.6 \%)$ & $33(75 \%)$ & 0.08 & 0.04 \\
\hline
\end{tabular}

$\mathrm{P}$ value $^{1}$ is comparison of characters with $\mathrm{ABO}$ blood types, $\mathrm{P}$ value ${ }^{2}$ is comparison of characters with $\mathrm{O}$ against non $\mathrm{O}$ type

Evaluation of the clinicopathological characteristics according to $\mathrm{ABO}$ blood types $(\mathrm{O}$ and non $\mathrm{O}$ types) was done as shown in Table 2. PSA value, Gleason score, tumor stage, node positivity and bone metastasis showed no significant association $(\mathrm{p}=0.418$, $\mathrm{p}=0.967, \mathrm{p}=0.506, \mathrm{p}=0.775, \mathrm{p}=0.549$ ) to any particular blood group. Out of the 44 cases of high risk PCa, $33(75 \%)$ belonged to the non $\mathrm{O}$ blood groups and 11 $(25 \%)$ belonged to the $\mathrm{O}$ group. The non $\mathrm{O}$ blood groups as a whole showed a statistically significant association with high risk category of $\mathrm{PCa}(\mathrm{p}=0.04)$ on comparison with $\mathrm{O}$ group. In the non $\mathrm{O}$ group, groups $\mathrm{A}$ and $\mathrm{B}$ had a high risk percentage (31.8\% and 27.3\%) whereas the $\mathrm{AB}$ group had a low risk percentage (13.6\%) of developing PCa. This association was further analysed by regression analysis.

Table 3: Univariate logistic regression analysis in high risk PCa patients

\begin{tabular}{|l|c|c|}
\hline \multicolumn{1}{|c|}{ Characters } & Odds ratio & P value \\
\hline Hypertension & 0.419 & 0.009 \\
\hline Diabetes mellitus & 0.333 & 0.002 \\
\hline PSA & 13.6 & $<0.001$ \\
\hline Gleason score & 10.2 & 0.002 \\
\hline $\begin{array}{l}\text { O against non O blood } \\
\text { types }\end{array}$ & 3.000 & 0.002 \\
\hline
\end{tabular}

Univariate logistic regression analysis was used to correlate ABO Blood Types and other clinicopathological features with reference to high risk category. As shown in Table 3, parameters including hypertension, diabetes mellitus, PSA, Gleason score, and blood type $\mathrm{O}$ against non $\mathrm{O}$ were found to be statistically significant in univariate analyses $(\mathrm{p}=0.009$, $\mathrm{p}=0.002, \mathrm{p}=<0.001, \mathrm{p}=0.002$ and $\mathrm{p}=0.002$ ) and further, were analysed by multivariate analysis. The significance of PSA, Gleason score and $\mathrm{O}$ against non $\mathrm{O}$ blood types in high risk $\mathrm{PCa}$ patients persisted $(p<0.001)$ after adjusting for the confounding factors. From the above results, we inferred that non $\mathrm{O}$ blood groups can be used as a predictor for aggressive PCa. The association of age, hypertension, diabetes mellitus and high risk PCa was nulled on multivariate analysis.

\section{Discussion}

Prostate cancer (PCa) is the second most common cancer occurring in Indian males. With increasing expectancy of life, more number of elderly men alive and changing lifestyles, the incidence of $\mathrm{PCa}$ is on the raise. PSA, TNM stage and Gleason score are known risk factors of PCa. ${ }^{1,2}$ Significance of ABO blood types in several cancer types is well established. In the year 1953, Arid et al for the first time revealed an association between $\mathrm{ABO}$ blood types and gastric carcinoma, ${ }^{7}$ ever since till date many investigators have extensively researched on the clinicopathological significance of $\mathrm{ABO}$ blood groups in different human cancers.

In the Indian setup, where the ethnic, demographic and racial characters are different from other setups where similar studies were undertaken, there is a paucity of studies which evaluate the significance of 
clinicopathological characters in relation to the blood group types in patients with PCa. Hence the present study was undertaken, the first one of its kind in Indian setup. We concluded that $\mathrm{O}$ blood type had a lower risk of developing $\mathrm{PCa}$ and the tumor behaved less aggressively in comparison with non $\mathrm{O}$ blood types. This association remained independent and significant on multivariate analysis after adjusting for the confounding factors. Our study has provided thoughtful insights into the clinical importance of $\mathrm{ABO}$ typing in PCa patients with regard to the risk assessment.

$\mathrm{ABO}$ surface antigens are highly expressed on RBC membranes, tissues, most epithelial and endothelial cells. These antigens help in adhesion, maintaining membrane structural integrity, and transportation of molecules across membranes. ${ }^{8}$

The association between $\mathrm{ABO}$ blood groups and leukemias- Acute lymphoblastic leukemia was proven to be significant with an increase in risk for $\mathrm{AB}$ blood type. ${ }^{9}$ The non $\mathrm{O}$ blood group type patients had an increased risk of head \& neck cancers, pancreatic cancer, ovarian cancer, renal cancer and gastric cancer. $^{10-14}$

We reviewed the literature for studies on clinicapathological risk factors for PCa and found that, Markt et al in their study of 2,774 cases had reported no difference between varied blood group types and risk of PCa. ${ }^{15}$ On the contrary a study by Wang et al on 277 cases revealed that patients with non $\mathrm{O}$ blood type had greater risk of aggressive $\mathrm{PCa}$, suggesting that non $\mathrm{O}$ cases should be given more clinical attention ${ }^{3}$.

In our study, we studied the association of $\mathrm{ABO}$ blood types and other clinicopathological features with regard to the risk in PCa cases. We established that the non $\mathrm{O}$ blood groups are an important predictor and prognostic factor for aggressive $\mathrm{PCa}$, serving it as a primary marker for high risk PCa. Incidence of node positivity and distant metastasis remained same irrespective of the blood group type, however the general trend of $\mathrm{O}$ blood type association with low risk prevailed.

The outcome of present study is in concordance with other studies where an association was found between the non $\mathrm{O}$ blood groups and cancers like gastric, pancreatic, breast, colorectal, ovarian, nasopharyngeal and esophageal cancer. ${ }^{12,5}$ Therefore, our data has thrown light with regard to the clinical application of $\mathrm{ABO}$ blood types in cancers.

Considering the complexity of mechanisms involved in tumorigenesis, the uncertain role of $\mathrm{ABO}$ blood types in them and given the association of specific blood groups in certain cancers, further studies in this regard are a need of the hour. Based on the results of the present study, we suggest patients of the non $\mathrm{O}$ blood groups may have an increased risk and should be evaluated thoroughly.

Non $\mathrm{O}$ blood type $\mathrm{PCa}$ cases require a more aggressive treatment protocol with radical prostatectomies. It was found that patients with $\mathrm{B}$ and $\mathrm{O}$ blood groups faired better with vaccine therapy in comparison with other groups, thus stressing on the need for blood group evaluation in PCa patients. Blood grouping may act as a cost effective tool for selection of patients who have a chance to benefit from vaccine therapy. ${ }^{16}$

Recurrence rates of prostate cancer was low in $\mathrm{O}$ blood types further supporting our findings of association of $\mathrm{O}$ blood type with low risk prostate cancer. ${ }^{17}$

Limitations of the present study were 1 . Being an observational, cross sectional study, the long term prognostic outcome of these patients was not analysed. 2. Single centre study. 3. Small case number. Given, the outcome of the present study, large multicentre studies in this regard are needed to throw more light in this unexplored area.

\section{Conclusion}

The present study has provided first hand evidence regarding the association between the non $\mathrm{O}$ blood groups and increased risk of aggressive PCa. We conclude that non $\mathrm{O}$ blood type can be a predictor of high risk PCa. Further genetic and molecular research is needed in this regard to establish the mechanisms involved in the blood group- tumor association.

\section{References}

1. Ferlay J., Shin H.R., Bray F. International Agency for Research on Cancer; Lyon, France: 2010. GLOBOCAN 2008, Cancer Incidence and Mortality Worldwide: IARC Cancer Base No. 10.

2. Jain, Shalu, Sunita Saxena, and Anup Kumar. "Epidemiology of Prostate Cancer in India." Meta Gene 2. 2014; 596-605.

3. Fang-Ming W, Yan Z, Gui-Ming Z, Ya-Nan L, Li-Jiang S. "Association of ABO Blood Types and Clinicopathological Features of Prostate Cancer'. Disease Markers, vol. 2017, Article ID 9237481, 6 pages, 2017.

4. Liumbruno GM, Franchini M. "Beyond immunohaematology: the role of the ABO blood group in human diseases', Blood Transfusion. 2013;11(4):491499.

5. Sun W, Wen C-P, Lin J, et al. "ABO blood types and cancer risk-A cohort study of 339,432 subjects in Taiwan', Cancer epidemiology. 2015;39(2):150-156.

6. I. Epstein, W. C. Allsbrook Jr., M. B. Amin, L. L. Egevad, and ISUP Grading Committee. The 2005 International Society of Urological Pathology (ISUP) consensus conference on Gleason grading of prostatic carcinoma," The American Journal of Surgical Pathology, 2005;29:1228- 1242.

7. I. Arid, H. H. Bentall, and J. A. Roberts, "A relationship between cancer of stomach and the ABO blood groups". British Medical Journal. 1953;(1):799-801.

8. M.E. Reid and N. Mohandas, "Red blood cell blood group antigens: structure and function". Seminars in Hematology. 2004;41:93-117.

9. Alavi S, Ashraf H, Rashidi A, Hosseini N, Abouzari M. "Distribution of ABO blood groups in childhood acute leukemia', Pediatr Hematol Oncol. 2006;23(8):611-7. 
10. Kassiani K, Ioannis K, Ioannis K, Savvas D, Paulos S. "Relationship between ABO blood groups and head and neck cancer among Greek patients'. JBUON. 2016;21(3):595.

11. Henderson J, Seagroatt V, Goldacre M. "Ovarian canser and ABO blood groups". J Epidemiol Community Health. 1993;47(4):287-9.

12. Kyungtae K, Young H P, Chang W J, Ja Hyeon Ku, Hyeon H K, et al, "Prognostic Significance of Blood Type A in Patients with Renal Cell Carcinoma". 2016;13(4):2766.

13. Julia B Greer, Mark H Yazer, Jay S Raval, M Michael Barmada, Randall E Brand, et al "Significant association between $\mathrm{ABO}$ blood group and pancreatic cancer". World J Gastroenterol. 2010;16(44):5588-5591.

14. Wang Z, Liu L, Ji J, et al. “ABO Blood Group System and Gastric Cancer: A Case-Control Study and MetaAnalysis". International Journal of Molecular Sciences. 2012;13(10):13308-13321.

15. Markt SC, Shui IM, Unger RH. ABO Blood Group Alleles and Prostate Cancer Risk: Results from the Breast and Prostate Cancer Cohort Consortium (BPC3)". The Prostate. 2015;75(15):1677-1681.
16. Muthana SM, Gulley JL, Hodge JW, Schlom J, Gildersleeve JC. "ABO blood type correlates with survival on prostate cancer vaccine therapy". Oncotarget. 2015;6(31):32244-32256.

17. European Association of Urology. "Recurrence of prostate cancer is significantly lower in men with blood group O." Science Daily. Science Daily, 14 April 2014. <www.sciencedaily.com/releases/2014/04/140414091907 $. h t m>$.

How to cite this article: Shankar S, Prasad CSBR. Clinicopathological study of $\mathrm{ABO}$ blood types in prostate cancer. Indian $\mathrm{J}$ Pathol Oncol. 2018;5(4):675-679. 